\title{
Corrigendum
}

\section{Searching for mammary analog secretory carcinoma of salivary gland among its mimics}

Andre Pinto, Vania Nosé, Claudia Rojas, Yao-Shan Fan and Carmen Gomez-Fernandez Modern Pathology (2014) 27, 918; doi:10.1038/modpathol.2014.45

Correction to: Modern Pathology (2014) 27, 30-37; doi:10.1038/modpathol.2013.84; published online 28 June 2013
In the title of this article, the word 'analog' should be 'analogue.' 